\title{
Redução do acamamento em aveia-branca com uso do regulador de crescimento etil-trinexapac
}

\author{
Maraisa Crestani Hawerroth(1), José Antonio Gonzalez da Silva(2), Clovis Arruda Souza(3), \\ Antonio Costa de Oliveira ${ }^{(4)}$, Henrique de Souza Luche ${ }^{(4)}$, Cristiano Mathias Zimmer ${ }^{(4)}$, \\ Fernando José Hawerroth ${ }^{(5)}$, Jordana Schiavo(2) e Julhana Cristina Sponchiado(3)
}

\begin{abstract}
(1)Empresa de Pesquisa Agropecuária e Extensão Rural de Santa Catarina, Estação Experimental de Caçador, Rua Abílio Franco, no 1.500, Bom Sucesso, Caixa Postal 351, CEP 89500-000 Caçador, SC, Brasil. E-mail: maraisacrestani@gmail.com (2)Universidade Regional do Noroeste do Estado do Rio Grande do Sul, Departamento de Estudos Agrários, Rua do Comércio, no 3.000, Bairro Universitário, CEP 98700-000 ljuí, RS, Brasil. E-mail: jagsfaem@yahoo.com.br, jordana.s09@gmail.com (3)Universidade do Estado de Santa Catarina, Departamento de Agronomia, Avenida Luís de Camões, oㅡ 2.090, Conta Dinheiro, CEP 88520-000 Lages, SC, Brasil. E-mail: clovis.souza@udesc.br, julhanasponchiado@gmail.com (4)Universidade Federal de Pelotas, Departamento de Fitotecnia, Campus Universitário Capão do Leão, Caixa Postal 354, CEP 96010-900 Pelotas, RS, Brasil. E-mail: acostol@cgfufpel.org, hluche@gmail.com, cmz.zimmer@gmail.com ${ }^{(5)}$ Embrapa Uva e Vinho, Estação Experimental de Fruticultura de Clima Temperado, BR 285, Km 4, Caixa Postal 1513, CEP 95200-000 Vacaria, RS, Brasil. E-mail: fernando.hawerroth@embrapa.br
\end{abstract}

Resumo - O objetivo deste trabalho foi avaliar os efeitos da aplicação de concentrações do regulador de crescimento etil-trinexapac na altura de planta, no acamamento e na produtividade de grãos da cultivar de aveia-branca Barbarasul, em diferentes ambientes de cultivo e doses de nitrogênio. Os experimentos foram conduzidos nas safras 2010 e 2011 nos municípios de Capão do Leão e Augusto Pestana, no Estado do Rio Grande do Sul, e nas safras 2010 e 2012 no Município de Lages, no Estado de Santa Catarina. Utilizou-se o delineamento de blocos ao acaso, em arranjo fatorial $4 \times 2 \times 6$ (dose de etil-trinexapac, estádio de desenvolvimento da planta e ambiente), com quatro repetições constituídas por parcelas úteis de 3,0 $\mathrm{m}^{2}$. Em cada ambiente, realizou-se adubação nitrogenada com 30 e $90 \mathrm{~kg} \mathrm{ha}^{-1} \mathrm{de}$ N. Foram avaliados os caracteres altura de planta, percentagem de acamamento e produtividade de grãos. A aplicação do regulador de crescimento etil-trinexapac nas doses de 100 a $150 \mathrm{~g}$ i.a. ha ${ }^{-1} \mathrm{em}$ plantas de aveia-branca 'Barbarasul', nos estádios $\mathrm{E}_{31}$ e $\mathrm{E}_{32}$, reduz a altura das plantas e a percentagem de acamamento, sem prejuízos à produtividade de grãos. A intensidade da redução do acamamento depende das características do ambiente de cultivo.

Termos para indexação: Avena sativa, altura de planta, biossíntese de giberelinas, produtividade de grãos.

\section{Lodging reduction in white oat using the plant growth regulator trinexapac-ethyl}

\begin{abstract}
The objective of this work was to evaluate the effects of the application of doses of the plant growth regulator trinexapac-ethyl on plant height, lodging index, and grain yield of the white oat cultivar Barbarasul at different cultivation environments and nitrogen doses. The experiments were conducted in the 2010 and 2011 crop seasons in the municipalities of Capão do Leão and Augusto Pestana, in the state of Rio Grande do Sul, and in the 2010 and 2012 crop seasons in the municipality of Lages, in the state of Santa Catarina, Brazil. A randomized complete block design was used, in a $4 \times 2 \times 6$ factorial arrangement (dose of trinexapac-ethyl, development stage, and environment), with four replicates consisting of $3.0 \mathrm{~m}^{2}$ plots. In each environment, nitrogen fertilization was done with 30 and $90 \mathrm{~kg} \mathrm{ha}^{-1} \mathrm{~N}$. The evaluated traits were plant height, lodging index percentage, and grain yield. The application of the growth regulator trinexapac-ethyl, at the doses of 100 to $150 \mathrm{~g}$ a.i. $\mathrm{ha}^{-1}$ in 'Barbarasul' white oat plants, in the $\mathrm{E}_{31}$ and $\mathrm{E}_{32}$ development stages, reduces plant height and the percentage of lodging, without harming grain yield. The intensity of the reduction in lodging depends on the conditions of the cultivation environment.
\end{abstract}

Index terms: Avena sativa, plant height, gibberellin biosynthesis, grain yield.

\section{Introdução}

O melhoramento genético de aveia-branca (Avena sativa L.) no Brasil permitiu o desenvolvimento de genótipos superiores em termos de produtividade de grãos e mais ajustados aos principais sistemas de cultivo (Oliveira et al., 2012a, 2012b). Dessa forma, o País se tornou um produtor de aveia-branca de elevada qualidade, o que atende grande parte da demanda nacional. A aveia é o quinto cereal mais cultivado no Brasil e está entre as dez principais culturas anuais, 
com aproximadamente 214 mil hectares em 2013, com produção total de 479 mil toneladas de grãos e produtividade média de $2.230 \mathrm{~kg} \mathrm{ha}^{-1}$ (Instituto Brasileiro de Geografia e Estatística, 2014).

A utilização de cultivares de aveia-branca mais produtivas e responsivas à adubação tem acarretado o uso mais intenso de fertilizantes nitrogenados, associado às técnicas de manejo que buscam otimizar o aproveitamento espacial da lavoura, como o aumento da densidade de semeadura. Essas práticas, apesar de contribuírem para o incremento da produtividade de grãos (Ceccon et al., 2004), aumentam os riscos de ocorrência de acamamento de plantas, com consequências na qualidade e no rendimento de grãos (Mohr et al., 2007). Assim como em outros cereais, o acamamento de plantas caracteriza um problema recorrente nas lavouras de aveia-branca (Oliveira et al., 2011).

A aveia-branca é cultivada de forma mais expressiva nos estados do Rio Grande do Sul e do Paraná, e, em menores áreas, em Santa Catarina e São Paulo, cujas regiões de cultivo apresentam características edafoclimáticas bastante distintas (Instituto Brasileiro de Geografia e Estatística, 2014). Em resposta aos diferentes ambientes de cultivo, observa-se grande variação no desempenho das cultivares de aveia-branca quanto à ocorrência do acamamento de plantas, em uma mesma safra (Oliveira et al., 2011). Fatores de ambiente, que variam ao longo das safras de cultivo em um mesmo local, podem potencializar a ocorrência do acamamento de plantas, com destaque para elevada incidência de ventos, maior ocorrência de chuvas e diferentes condições do solo, como maior teor de $\mathrm{N}$ disponível (Berry et al., 2003).

O acamamento em cereais é um fenômeno complexo, resultante de fatores intrínsecos ao genótipo, às características de solo, às condições climáticas e às práticas culturais adotadas. No que diz respeito ao genótipo, os conteúdos de celulose, hemicelulose e lignina, especialmente em nós e entrenós basais, assim como a altura da planta, são caracteres fortemente associados à resistência ou à suscetibilidade ao acamamento (Tripathi et al., 2003; Zhu et al., 2004).

A altura de plantas de aveia-branca está intimamente relacionada à disponibilidade de nitrogênio no ambiente de cultivo (Mohr et al., 2007). Com o incremento de N, as plantas tendem a apresentar maior desenvolvimento vegetativo e aumento do comprimento dos entrenós. Nessas condições, ocorre maior sombreamento entre plantas, as quais recebem menor quantidade de radiação, o que resulta na modificação das propriedades biofísicas dos colmos e, consequentemente, numa menor resistência ao acamamento (Berry et al., 2000).

Para minimizar a ocorrência do acamamento de plantas em espécies cultivadas, têm-se avaliado o uso de reguladores de crescimento, como o etil-trinexapac, em culturas como as de soja (Glycine max) (Souza et al., 2013), arroz (Oryza sativa) (Arf et al., 2012), trigo (Triticum aestivum) (Berti et al., 2007; Zagonel \& Fernandes, 2007) e crotalária (Crotalaria juncea) (Kappes et al., 2011). Os reguladores de crescimento têm sido empregados para tornar a arquitetura das plantas mais adaptada e eficiente quanto ao uso dos recursos naturais e dos insumos, a fim de suportar elevados rendimentos agronômicos (Souza et al., 2013). Em cereais de inverno, o princípio ativo etil-trinexapac vem sendo utilizado em lavouras comerciais no Brasil, e seu uso tem sido indicado para a redução do crescimento das plantas em altura e para o fortalecimento dos entrenós. Embora haja escassez de informações científicas sobre os efeitos do uso de reguladores de crescimento na cultura da aveia-branca, essa prática pode ser uma alternativa para minimizar os efeitos negativos do acamamento de plantas (Rajala \& Peltonen-Sainio, 2001; Rajala, 2004; Witkowicz, 2010).

O objetivo desse trabalho foi avaliar os efeitos da aplicação de concentrações do regulador de crescimento etil-trinexapac na altura de planta, no acamamento e na produtividade de grãos da cultivar de aveia-branca Barbarasul, em diferentes ambientes de cultivo e doses de nitrogênio.

\section{Material e Métodos}

Os ensaios foram conduzidos em três locais com condições edafoclimáticas distintas. Nas safras 2010 e 2011, os experimentos foram realizados nos municípios de Augusto Pestana, RS $\left(28^{\circ} 27^{\prime} \mathrm{S}, 53^{\circ} 54^{\prime} \mathrm{W}\right.$, a $328 \mathrm{~m}$ de altitude), em Latossolo Vermelho distroférrico típico (Santos et al., 2006); e de Capão do Leão, RS ( $31^{\circ} 45^{\prime} \mathrm{S}, 52^{\circ} 29^{\prime} \mathrm{W}$, a $13 \mathrm{~m}$ de altitude), em Argissolo Vermelho-Amarelo distrófico (Santos et al., 2006). Já nas safras 2010 e 2012, os experimentos foram conduzidos no Município de Lages, SC $\left(27^{\circ} 52^{\prime} \mathrm{S}\right.$, $50^{\circ} 18^{\prime} \mathrm{W}$, a $930 \mathrm{~m}$ de altitude), em Cambissolo Húmico alumínico argiloso (Santos et al., 2006). Os dados meteorológicos referentes à precipitação pluvial e às temperaturas locais (máximas, médias e mínimas) 
observadas no período de cultivo, da semeadura à colheita, estão descritos na Tabela 1.

Com base nos resultados das avaliações conjuntas de cultivares recomendadas para o cultivo no Brasil, optou-se por utilizar, no presente trabalho, a cultivar Barbarasul. Essa cultivar foi lançada em 2008, por apresentar elevado potencial produtivo, reduzida altura de planta, em média $101 \mathrm{~cm}$ em ambientes de cultivo no Sul do Brasil, e tolerância ao acamamento (Carvalho et al., 2009). Esse desempenho, contudo, é expresso em ambientes específicos (Lângaro et al., 2010, 2013), como observado no cultivo em diferentes locais em uma mesma safra, quando ocorre o acamamento de plantas em ambientes cujas condições são favoráveis.

O preparo do solo das áreas experimentais seguiu as recomendações da Comissão Brasileira de Pesquisa de Aveia (Comissão Brasileira de Pesquisa de Aveia, 2006), tendo sido realizadas correções da acidez e adubação com os macronutrientes $\mathrm{P}$ e K em função dos teores verificados na análise química e granulométrica do solo, em cada área e ano de cultivo (Tabela 2). Em Augusto Pestana, as áreas de implantação dos experimentos são rotineiramente cultivadas em sistema de semeadura direta, com o cultivo de soja no período de verão e de aveia-branca ou trigo no período de inverno. Em Capão do Leão, tradicionalmente adotase o sistema de cultivo convencional, com cultivo de feijão miúdo na estação de verão e de aveia-branca ou trigo no inverno. Em Lages, nas áreas experimentais, é adotado o sistema de semeadura direta, com o cultivo de feijão na estação de verão e de aveia-branca no inverno.

Para avaliar o efeito da adubação nitrogenada, foram conduzidos dois experimentos em cada ambiente (local e safra), com 30 e $90 \mathrm{~kg} \mathrm{ha}^{-1}$ de $\mathrm{N}$, aplicadas no momento da semeadura e em cobertura, para se obter os níveis desejados. Essa aplicação foi realizada quando as plantas apresentavam as quatro primeiras folhas do colmo principal visíveis, isto é, estavam no estádio 14 da escala de Zadoks (Zadoks et al., 1974), com N disponibilizado na forma de ureia, na concentração de $44 \%$. De acordo com a necessidade de cada local, foram efetuadas aplicações do fungicida tebuconazole, na dosagem de $0,75 \mathrm{~L} \mathrm{ha}^{-1}$ [i.a. $150 \mathrm{~g} \mathrm{ha}^{-1}$ do produto comercial Folicur CE (Bayer CropScience, São Paulo, $\mathrm{SP})]$.

Tabela 1. Dados meteorológicos médios para o período de cultivo ${ }^{(1)}$ da aveia-branca (Avena sativa) 'Barbarasul', avaliada em diferentes ambientes (locais e safras) com uso do regulador de crescimento etil-trinexapac.

\begin{tabular}{|c|c|c|c|c|}
\hline \multirow[t]{2}{*}{ Ambiente de avaliação } & \multicolumn{3}{|c|}{ Temperatura } & \multirow{2}{*}{$\begin{array}{l}\text { Precipitação acumulada } \\
(\mathrm{mm})\end{array}$} \\
\hline & Máxima $\left({ }^{\circ} \mathrm{C}\right)$ & Mínima $\left({ }^{\circ} \mathrm{C}\right)$ & Média $\left({ }^{\circ} \mathrm{C}\right)$ & \\
\hline 1. Augusto Pestana, RS, safra 2010 & 23,10 & 10,26 & 16,81 & 563,4 \\
\hline 2. Augusto Pestana, RS, safra 2011 & 22,95 & 10,34 & 16,55 & 813,0 \\
\hline 3. Capão do Leão, RS, safra 2010 & 20,12 & 10,43 & 14,73 & 477,8 \\
\hline 4. Capão do Leão, RS, safra 2011 & 20,58 & 11,64 & 15,61 & 395,5 \\
\hline 5. Lages, SC, safra 2010 & 20,99 & 10,79 & 15,29 & 602,0 \\
\hline 6. Lages, SC, safra 2012 & 21,06 & 11,10 & 15,94 & 434,0 \\
\hline
\end{tabular}

(1)Períodos do cultivo à colheita em cada ambiente: 1, 20/6 a 9/11/2010; 2, 10/6 a 1/11/2011; 3, 29/6 a 20/11/2010; 4, 14/7 a 2/12/2011; 5, 30/7 a 19/12/2010; e 6,16/7 a 4/12/2012. Dados coletados na Estação Agroclimática de Pelotas, em Capão do Leão, RS; no Instituto Regional de Desenvolvimento Rural, em Augusto Pestana, RS; e no Laboratório de Meteorologia da Universidade do Estado de Santa Catarina, em Lages, SC.

Tabela 2. Características do solo nos diferentes ambientes (locais e safras) de avaliação da aveia-branca (Avena sativa) 'Barbarasul', em resposta ao uso do regulador de crescimento etil-trinexapac.

\begin{tabular}{lccccccccc}
\hline Ambiente de avaliação & $\begin{array}{c}\text { Índice } \\
\mathrm{SMP}\end{array}$ & $\begin{array}{c}\mathrm{pH} \\
\mathrm{em} \mathrm{H} \mathrm{H}_{2} \mathrm{O}\end{array}$ & $\begin{array}{c}\mathrm{MO} \\
\left(\mathrm{g} \mathrm{kg}^{-1}\right)\end{array}$ & $\begin{array}{c}\mathrm{P} \\
--\left(\mathrm{mg} \mathrm{dm}^{-3}\right)--\end{array}$ & $\begin{array}{c}\mathrm{CTC}_{\mathrm{pH}} \text { 7 } \\
----\left(\mathrm{cmol}_{\mathrm{c}} \mathrm{dm}^{-3}\right)----\end{array}$ & $\begin{array}{c}\mathrm{CTC}_{\text {efetiva }} \\
\mathrm{V} \\
(\%)\end{array}$ & $\begin{array}{c}\text { Argila } \\
\left(\mathrm{g} \mathrm{kg}^{-1}\right)\end{array}$ \\
\hline Augusto Pestana, RS, safra 2010 & 6,7 & 6,5 & 35 & 3,5 & 22,5 & 273,0 & 13,0 & 84,9 & 430 \\
Augusto Pestana, RS, safra 2011 & 6,8 & 6,7 & 34 & 3,4 & 19,4 & 219,0 & 11,2 & 83,0 & 430 \\
Capão do Leão, RS, safra 2010 & 6,4 & 5,8 & 20 & 2,0 & 21,1 & 116,0 & 7,6 & 61,0 & 190 \\
Capão do Leão, RS, safra 2011 & 6,6 & 6,0 & 21 & 2,1 & 22,8 & 123,0 & 8,0 & 65,0 & 210 \\
Lages, SC, safra 2010 & 6,6 & 6,3 & 27 & 2,7 & 45,1 & 110,0 & 20,7 & 89,4 & 340 \\
Lages, SC, safra 2012 & 6,3 & 5,9 & 39 & 3,9 & 30,0 & 222,0 & 13,6 & 77,2 & 330 \\
\hline
\end{tabular}


Nos experimentos com diferentes níveis de nitrogênio (30 e $90 \mathrm{~kg} \mathrm{ha}^{-1}$ ), foram realizados os tratamentos com doses do regulador de crescimento etil-trinexapac, nas concentrações de $0,50,100$ e $150 \mathrm{~g}$ i.a. ha ${ }^{-1}$ do produto comercial Moddus (Syngenta Crop Protection, São Paulo, SP), que contém $25 \%$ de ingrediente ativo. As aplicações foram realizadas em dois diferentes estádios de desenvolvimento das plantas: estádios de primeiro e de segundo nós visíveis no colmo em elongação, ou seja, nos estádios 31 e 32 da escala de Zadoks (Zadoks et al., 1974). As aplicações do regulador de crescimento foram realizadas por meio de aspersão com pulverizador costal, com volume médio de calda correspondente a $200 \mathrm{~L} \mathrm{ha}^{-1}$. Todos os experimentos foram conduzidos em delineamento experimental de blocos ao acaso, com quatro repetições, em arranjo fatorial 4x2x6 (dose do regulador de crescimento, estádio de desenvolvimento da planta e ambiente de cultivo). Na semeadura, foi adotada a densidade de 300 sementes viáveis por metro quadrado, com cada repetição formada por parcelas de cinco linhas de 5,0 m de comprimento espaçadas em $0,20 \mathrm{~m}$. As mensurações foram efetuadas com base nas três linhas centrais, o que caracterizou parcela útil de $3,0 \mathrm{~m}^{2}$.

No momento em que as plantas estavam em estádio de antese, isto é, no estádio 68 da escala de Zadoks (Zadoks et al., 1974), foi realizada a medição da altura de planta, desde rente ao solo até a extremidade da panícula, com avaliação ao acaso de dez plantas da parcela útil. No período próximo à maturidade de colheita, no estádio 87 da escala de Zadoks (Zadoks et al., 1974), foi mensurada a percentagem de plantas acamadas na parcela.

O índice de acamamento foi estimado visualmente e expresso em percentagem, tendo-se considerado o ângulo formado na posição vertical do colmo das plantas em relação ao solo e a área de plantas acamadas. Para essa estimativa, utilizou-se a metodologia sugerida por Moes \& Stobbe (1991), modificada, com o índice de acamamento (IA) definido a partir da seguinte equação: IA $(\%)=\mathrm{I} \times \mathrm{A} \times 2$, em que: I reflete o grau de inclinação das plantas, que varia de 0 a 5 , sendo que 0 é a ausência de inclinação e 5 são todas as plantas completamente acamadas; e A representa a área com plantas acamadas na parcela, que varia de 0 a 10 , sendo que 0 corresponde à ausência de plantas acamadas na parcela e 10 às plantas acamadas em toda a parcela, independentemente da sua inclinação.
Desse modo, essa equação pondera a incidência e a severidade do acamamento das plantas, por exemplo, quando têm-se I=5 e A=10, IA (\%) $=5 \times 10 \times 2=100 \%$, o que corresponde à existência de plantas acamadas rentes ao solo na área total da parcela.

Com a colheita de grãos da parcela útil, determinouse a produtividade de grãos, em $\mathrm{kg} \mathrm{ha}^{-1}$, com umidade corrigida para $13 \%$. Para atender às pressuposições da análise de variância, realizou-se a transformação dos dados referentes à variável percentagem de acamamento, em raiz quadrada do valor observado somado a $0,5:(x+0,5)^{0,5}$. Os dados foram submetidos à análise de variância para identificar os efeitos simples e de interação entre fatores de tratamento. Em seguida, foi feito o ajuste de regressão polinomial, em relação ao fator dose do regulador de crescimento, e foram comparadas as médias pelo teste de Tukey, a $5 \%$ de probabilidade. As análises foram realizadas com auxílio do programa computacional SAS (SAS Institute, 2002).

\section{Resultados e Discussão}

Quanto ao desempenho da aveia-branca 'Barbarasul', no ambiente que recebeu $30 \mathrm{~kg} \mathrm{ha}^{-1}$ de $\mathrm{N}$, foram observados, em relação ao caráteraltura de planta, efeitos significativos da interação tripla entre dose do regulador de crescimento (D), estádio de desenvolvimento (E) e ambiente (A), bem como interações simples e fatores principais (Tabela 3). Houve efeitos da interação DxA e dos fatores principais, dose do regulador de crescimento e ambiente, nos caracteres acamamento e produtividade de grãos. Assim, a cultivar Barbarasul apresentou altura de planta variável nos diferentes ambientes testados, a qual também foi afetada pela dose do regulador de crescimento e pelo estádio de desenvolvimento da planta. No entanto, os níveis de acamamento e a produtividade de grãos foram afetados apenas pelas características do ambiente e pelas doses do regulador de crescimento, sem interferência do estádio de desenvolvimento. A cultivar Barbarasul apresentou altura média de $84 \mathrm{~cm}$, acamamento de $8,1 \%$ das plantas e produtividade de grãos de $3.450,6 \mathrm{~kg} \mathrm{ha}^{-1}$.

Nos ambientes onde foram utilizados $90 \mathrm{~kg} \mathrm{ha}^{-1} \mathrm{de} \mathrm{N}$, houve efeito da interação tripla DxExA nos caracteres altura de planta e produtividade de grãos, enquanto as interações DxA e ExA apresentaram efeitos na altura de planta e no acamamento. $\mathrm{O}$ fator dose de etil-trinexapac 
(D) exerceu efeito nos caracteres altura de planta e acamamento; já o fator ambiente (A) apresentou efeito nos três caracteres avaliados. O estádio de desenvolvimento e a interação DxE não apresentaram efeitos significativos. Dessa forma, a altura de planta e a produtividade de grãos variaram de acordo com os diferentes ambientes testados, as doses do regulador de crescimento e os estádios de desenvolvimento, enquanto o acamamento variou apenas com o ambiente e as doses do regulador de crescimento. O estádio de desenvolvimento proporcionou desempenho geral diferenciado em cada ambiente testado. A altura média de planta foi de $87,9 \mathrm{~cm}$, o acamamento de $16,1 \%$ das plantas e a produtividade de grãos de $3.498,9 \mathrm{~kg} \mathrm{ha}^{-1}$.

Tanto a sensibilidade ao acamamento quanto a produtividade de grãos evidenciam herança complexa, ou seja, são governados por um grande número de genes de pequeno efeito e, portanto, são caracteres fortemente afetados pelas condições ambientais
(Tanhuanpää et al., 2012; Kong et al., 2013), o que justifica a variação e as magnitudes dos coeficientes de variação observados nas diferentes condições de cultivo avaliadas no presente trabalho.

Em ambas as doses de adubação nitrogenada, a aplicação do regulador proporcionou respostas significativas da altura de planta, a qual também foi modificada pela aplicação em diferentes estádios de desenvolvimento da planta, pela concentração do ingrediente ativo e pelo ambiente (local e safra) (Figura 1). Esse comportamento também foi constatado em avaliações com outras espécies de poaceas, como trigo (Berti et al., 2007; Espindula et al., 2010) e arroz (Arf et al., 2012). De acordo com as especificações do produto comercial, quando absorvido pela planta, o etil-trinexapac atua seletivamente na redução do nível de giberelina ativa e induz a planta à uma inibição temporária ou à redução do ritmo de crescimento,

Tabela 3. Análise de variância para os caracteres altura de planta, percentagem de acamamento e produtividade de grãos da aveia-branca (Avena sativa) 'Barbarasul', determinados em diferentes ambientes, com a aplicação de doses do regulador de crescimento etil-trinexapac, estádios de desenvolvimento e doses de N.

\begin{tabular}{|c|c|c|c|c|}
\hline \multirow[t]{2}{*}{ Fonte de variação } & \multirow[t]{2}{*}{ GL } & \multicolumn{3}{|c|}{ Quadrado médio } \\
\hline & & Altura de planta $(\mathrm{cm})$ & Acamamento (\%) & Produtividade de grãos $\left(\mathrm{kg} \mathrm{ha}^{-1}\right)$ \\
\hline & & \multicolumn{3}{|c|}{$30 \mathrm{~kg} \mathrm{ha}^{-1}$ de $\mathrm{N}$} \\
\hline Dose do regulador (D) & 3 & $6.126,43 * *$ & $43,94 * *$ & $1.916,386,00^{*}$ \\
\hline Época de aplicação (E) & 1 & $281,16^{*}$ & $1,79^{\mathrm{ns}}$ & $125,306,90^{\mathrm{ns}}$ \\
\hline Ambiente (A) & 5 & $4.470,60 * *$ & $27,34 * *$ & $96.504,840,00 * *$ \\
\hline $\mathrm{D} \times \mathrm{E}$ & 3 & $193,95^{*}$ & $2,38^{\mathrm{ns}}$ & $215,868,70^{\text {ns }}$ \\
\hline $\mathrm{D} \times \mathrm{A}$ & 15 & $446,97 * *$ & $3,35 * *$ & $1.120,106,00^{*}$ \\
\hline Ex A & 5 & $606,07 * *$ & $1,93^{\text {ns }}$ & $231,495,90^{\text {ns }}$ \\
\hline$D \times E \times A$ & 15 & $235,77 * *$ & $1,60^{\mathrm{ns}}$ & $528,336,90^{\mathrm{ns}}$ \\
\hline Bloco & 3 & 17,64 & 2,11 & $1.212,771,00$ \\
\hline Erro & 141 & 70,34 & 1,00 & $643,478,40$ \\
\hline Média geral & - & 84,02 & 8,09 & $3.450,57$ \\
\hline \multirow[t]{2}{*}{ CV $(\%)$} & - & 9,98 & 41,01 & 23,25 \\
\hline & & \multicolumn{3}{|c|}{$90 \mathrm{~kg} \mathrm{ha}^{-1}$ de N } \\
\hline Dose do regulador (D) & 3 & $7.149,75^{* *}$ & $130,42 * *$ & $154,864,10^{\mathrm{ns}}$ \\
\hline Época de aplicação (E) & 1 & $22,84^{\text {ns }}$ & $0,13^{\mathrm{ns}}$ & $148,397,50^{\mathrm{ns}}$ \\
\hline Ambiente (A) & 5 & $4.863,72 * *$ & $9,74 * *$ & $70.680,890,00 * *$ \\
\hline $\mathrm{D} \times \mathrm{E}$ & 3 & $104,62^{\mathrm{ns}}$ & $0,33^{\mathrm{ns}}$ & $454,185,60^{\mathrm{ns}}$ \\
\hline $\mathrm{D} \times \mathrm{A}$ & 15 & $264,57 * *$ & $10,88 * *$ & $591,632,80^{\mathrm{ns}}$ \\
\hline $\mathrm{E} \times \mathrm{A}$ & 5 & $730,03 * *$ & $9,33 * *$ & $528,607,90^{\text {ns }}$ \\
\hline $\mathrm{D} \times \mathrm{E} \times \mathrm{A}$ & 15 & $131,17 * *$ & $1,00^{\mathrm{ns}}$ & $814,982,10 * *$ \\
\hline Bloco & 3 & 32,36 & 2,28 & $1.521,994,00$ \\
\hline Erro & 141 & 58,47 & 43,95 & $358,057,20$ \\
\hline Média geral & - & 87,89 & 16,13 & $3.498,87$ \\
\hline CV $(\%)$ & - & 8,70 & 25,93 & 17,10 \\
\hline
\end{tabular}

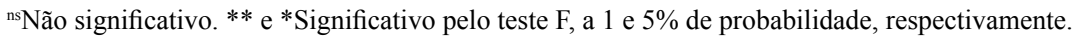


dependentemente da dose aplicada e das condições ambientais.

Houve diminuição da altura de planta com o uso de doses crescentes de etil-trinexapac (Figura 1). Entretanto, em Augusto Pestana, verificou-se resposta quadrática da altura de planta nas doses de $30 \mathrm{~kg} \mathrm{ha}^{-1}$ de $\mathrm{N}$, quando o produto foi aplicado em estádio de segundo nó visível $\left(E_{32}\right)$. As menores alturas foram verificadas na dose de $87,3 \mathrm{~g} \mathrm{ha}^{-1}$ de etil-trinexapac na safra 2010 (altura mínima $=-\mathrm{b} / 2 \mathrm{c}=82,2 \mathrm{~cm}$ ) e na dose de $136 \mathrm{~g} \mathrm{ha}^{-1}$ na safra $2011(75,1 \mathrm{~cm})$. Em Lages, na safra 2010, também constatou-se resposta quadrática da altura de planta com a aplicação do regulador em estádio de segundo nó visível, com 30 e $90 \mathrm{~kg} \mathrm{ha}^{-1}$ de N. Nesse ambiente, houve redução da altura de planta nas maiores concentrações do etil-trinexapac, superiores a $100 \mathrm{~g} \mathrm{ha}^{-1}$. Ainda nesse local, na safra 2012, com a aplicação em primeiro nó visível $\left(\mathrm{E}_{31}\right)$, a altura de planta apresentou desempenho cúbico, com as menores médias nas concentrações de $124 \mathrm{~g} \mathrm{ha}^{-1}(58,5 \mathrm{~cm}$, com $\left.30 \mathrm{~kg} \mathrm{ha}^{-1} \mathrm{de} \mathrm{N}\right)$ e $114 \mathrm{~g} \mathrm{ha}^{-1}\left(65,6 \mathrm{~cm}\right.$, com $90 \mathrm{~kg} \mathrm{ha}^{-1}$ de N). Nos demais ambientes, estádios e doses do regulador de crescimento, verificou-se diminuição linear da altura de planta com o uso de doses crescentes do etil-trinexapac. Logo, as doses mais efetivas para a redução da altura de planta encontraram-se no intervalo entre 100 e 150 g i.a. ha ${ }^{-1}$ de etil-trinexapac.

Outros estudos também mostraram efeito do etil-trinexapac na redução da altura de planta. No trigo, com o aumento da concentração de etil-trinexapac, observou-se tendência de redução linear da altura das plantas, com menores desempenhos no intervalo de 100 a 150 g i.a. ha-1 (Berti et al., 2007; Zagonel \& Fernandes, 2007). Na cultura do arroz, Arf et al. (2012) constataram a redução da altura em cultivares tratadas com doses de 50,100 e 150 g i.a. ha ${ }^{-1}$ no momento da diferenciação do primórdio da panícula, o que também proporcionou ausência de acamamento das plantas. Já a redução linear da altura de plantas de crotalária foi proporcionada com a aplicação de doses crescentes de etil-trinexapac, no intervalo de 75 a 300 g i.a. ha ${ }^{-1}$ (Kappes et al., 2011).

A época de aplicação do etil-trinexapac promoveu alturas variáveis de planta nos ambientes testados, nas diferentes condições de adubação nitrogenada, em que, ora a aplicação no estádio de primeiro nó visível, ora no de segundo nó visível resultou em maior redução da altura. Essa instabilidade de resposta nos diferentes estádios de desenvolvimento da planta também foi relatada em avaliações com cultivares de trigo, em Berti et al. (2007) e Penckowski et al. (2010). Segundo esses autores, houve maior redução da altura de planta com a aplicação em primeiro nó visível, em algumas cultivares, enquanto, em outras, essa resposta ocorreu quando o etil-trinexapac foi aplicado com o segundo nó visível. Zagonel \& Fernandes (2007) obtiveram plantas de trigo mais baixas com aplicações mais tardias, com o segundo nó visível.

Uma forte associação entre a ocorrência do acamamento e a altura de plantas em gramíneas, particularmente quando há maior disponibilidade de nitrogênio às plantas, foi demonstrada por Mohr et al. (2007) e Penckowski et al. (2010). Do mesmo modo, no presente trabalho, verificou-se o dobro da incidência média de acamamento com uso de $90 \mathrm{~kg} \mathrm{ha}^{-1}$ de $\mathrm{N}$ $(16,1 \%)$, em comparação a $30 \mathrm{~kg} \mathrm{ha}^{-1}$ de $\mathrm{N}(8,1 \%)$ (Tabela 3). Contudo, independentemente da aplicação do etil-trinexapac realizada no estádio 31 ou 32 da escala de Zadoks (Zadoks et al., 1974), houve diminuição do acamamento com o aumento das doses do regulador de crescimento em grande parte dos ambientes avaliados (Figura 2). Na adubação com $30 \mathrm{~kg} \mathrm{ha}^{-1}$ de $\mathrm{N}$, houve tendência linear de diminuição do acamamento com o aumento da concentração de etil-trinexapac. Porém, na safra 2011, em Augusto Pestana, o acamamento das plantas apresentou resposta quadrática, com valores mínimos atingidos na dose de $107,7 \mathrm{~g} \mathrm{ha}^{-1}(0,63 \%)$. Já em Capão do Leão, na safra 2011, e em Lages, na safra 2012, não foram observados efeitos significativos do uso do etil-trinexapac no acamamento de plantas, tendo-se obtido médias para essa variável de 1,7 e $6,6 \%$, respectivamente.

Com a maior dose de $\mathrm{N}\left(90 \mathrm{~kg} \mathrm{ha}^{-1}\right)$, na maioria dos ambientes testados, o acamamento apresentou resposta quadrática, com índices inferiores a 5\% nas seguintes concentrações de etil-trinexapac: 107,4 $\mathrm{g} \mathrm{ha}^{-1}$, em Augusto Pestana, na safra 2010; 109,5 $\mathrm{g} \mathrm{ha}^{-1}$, em Augusto Pestana, na safra 2011; 148,5 $\mathrm{g} \mathrm{ha}^{-1}$, em Capão do Leão, na safra 2010; e $150 \mathrm{~g} \mathrm{ha}^{-1}$, em Lages, na safra 2010. Em Capão do Leão, na safra 2011, os índices de acamamento diminuíram linearmente com o aumento das doses do fitorregulador, enquanto em Lages, na safra 2012, o etil-trinexapac não apresentou efeito, com média de 10,27\%. A ausência de resposta da aplicação do etil-trinexapac foi observada quando os menores índices de acamamento foram obtidos nas 
parcelas testemunha (sem aplicação), o que indica que as características do ambiente de cultivo não foram favoráveis para a ocorrência do acamamento de plantas. Em Lages, durante a safra 2012, ocorreu menor precipitação acumulada $(434 \mathrm{~mm})$ do que em 2010 (602 mm), o que pode ter contribuído para a menor eficiência de aproveitamento do $\mathrm{N}$ mineral disponibilizado às plantas, tanto em 30 quanto em $90 \mathrm{~kg} \mathrm{ha}^{-1}$ de $\mathrm{N}$, e para a menor ação potencial das chuvas (pressão mecânica sobre as plantas) na ocorrência do acamamento. Em Capão do Leão, o uso de $30 \mathrm{~kg} \mathrm{ha}^{-1}$ de $\mathrm{N}$ na safra 2011, mesmo com maior
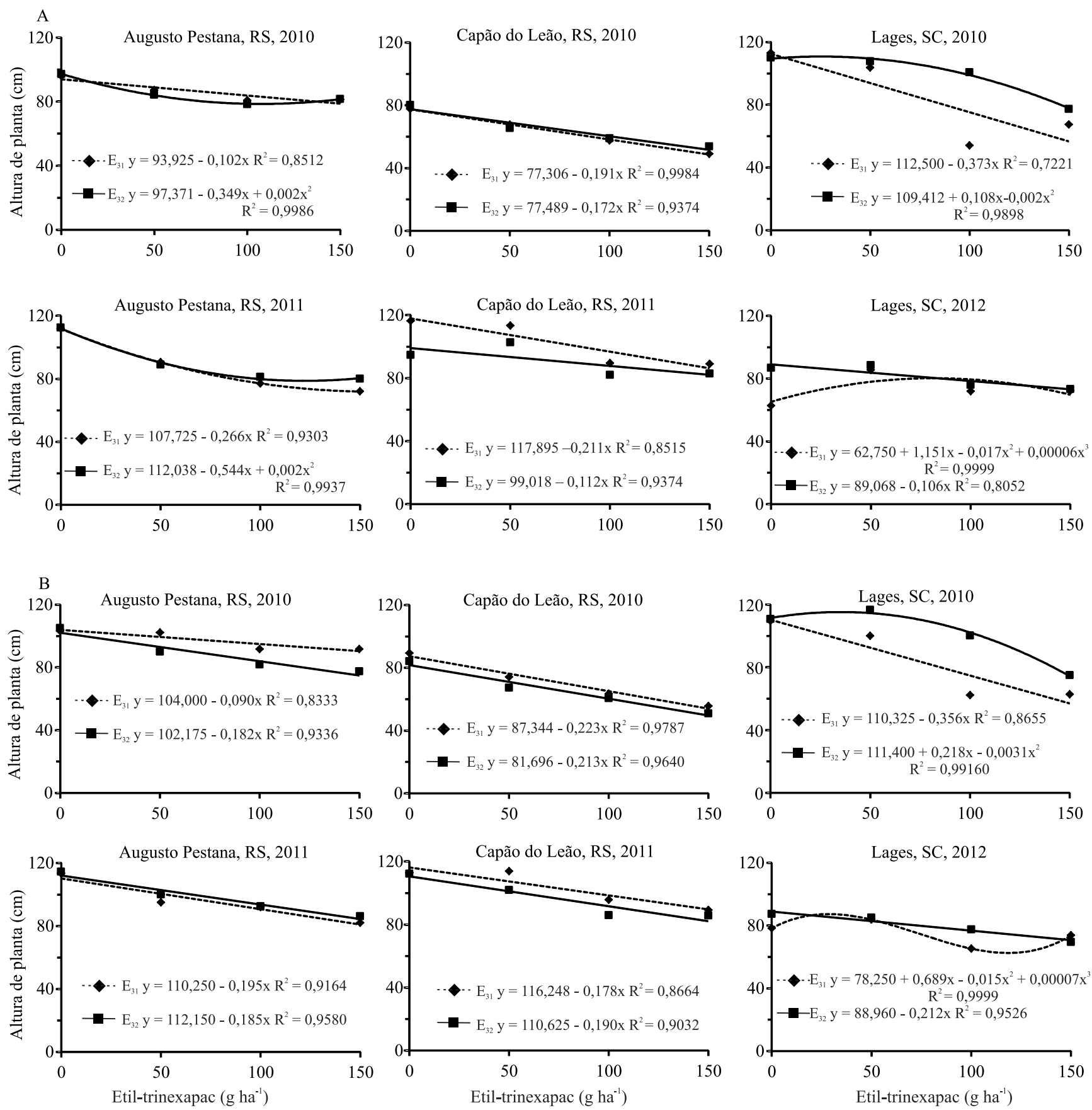

Figura 1. Altura de planta da aveia-branca (Avena sativa) 'Barbarasul' cultivada em diferentes ambientes, em resposta à aplicação de doses de etil-trinexapac nos estádios de primeiro e segundo nó visível, ou seja, nos estádios $31\left(\mathrm{E}_{31}\right)$ e $32\left(\mathrm{E}_{32}\right)$ da escala de Zadoks (Zadoks et al., 1974). A, adubação com $30 \mathrm{~kg} \mathrm{ha}^{-1}$ de N; B, adubação com $90 \mathrm{~kg} \mathrm{ha}^{-1}$ de N. 
disponibilidade híbrida $(477,8 \mathrm{~mm})$ do que a safra 2010 (395,5 mm), não favoreceu a ocorrência do acamamento de plantas, tendo resultado na diminuição inexpressiva do acamamento de plantas com doses crescentes do etil-trinexapac. Isso pode estar associado a menor ocorrência de outros fatores que favorecem o acamamento de plantas, como, por exemplo, ventos fortes e chuvas torrenciais durante o período de cultivo.

Nos ambientes com maiores índices pluviométricos (Tabela 1), associados à maior adubação nitrogenada, houve maior efetividade de ação do regulador de crescimento. Portanto, o uso do etil-trinexapac se mostra importante quando ministrado em ambientes mais propícios à ocorrência de acamamento de plantas.
No conjunto dos ambientes testados, o índice de acamamento médio variou de $5,6 \%$, na dose de 100 i.a. g ha ${ }^{-1}$ de etil-trinexapac, a 2,8\%, na de 150 i.a. $\mathrm{g} \mathrm{ha}^{-1}$, nos ambientes adubados com $30 \mathrm{~kg} \mathrm{ha}^{-1} \mathrm{de}$ N. Nos ambientes em que se aplicou 100 e 150 g i.a. ha ${ }^{-1}$ de etil-trinexapac, com $90 \mathrm{~kg} \mathrm{ha}^{-1}$ de $\mathrm{N}$, a variação foi de 6,9 a 5,2\%, respectivamente (Figura 2). Não houve diferença quanto ao acamamento de plantas entre ambientes e entre épocas de aplicação. Contudo, em Capão do Leão, na safra 2011, com uso de $90 \mathrm{~kg} \mathrm{ha}^{-1}$ de $\mathrm{N}$ e a aplicação do regulador com o primeiro nó visível, observou-se índice de acamamento superior ao constado com a aplicação com o segundo nó visível $\left(E_{31}=30 \%\right.$ e $E_{32}=15,6 \%$, respectivamente $)$. Em Lages,
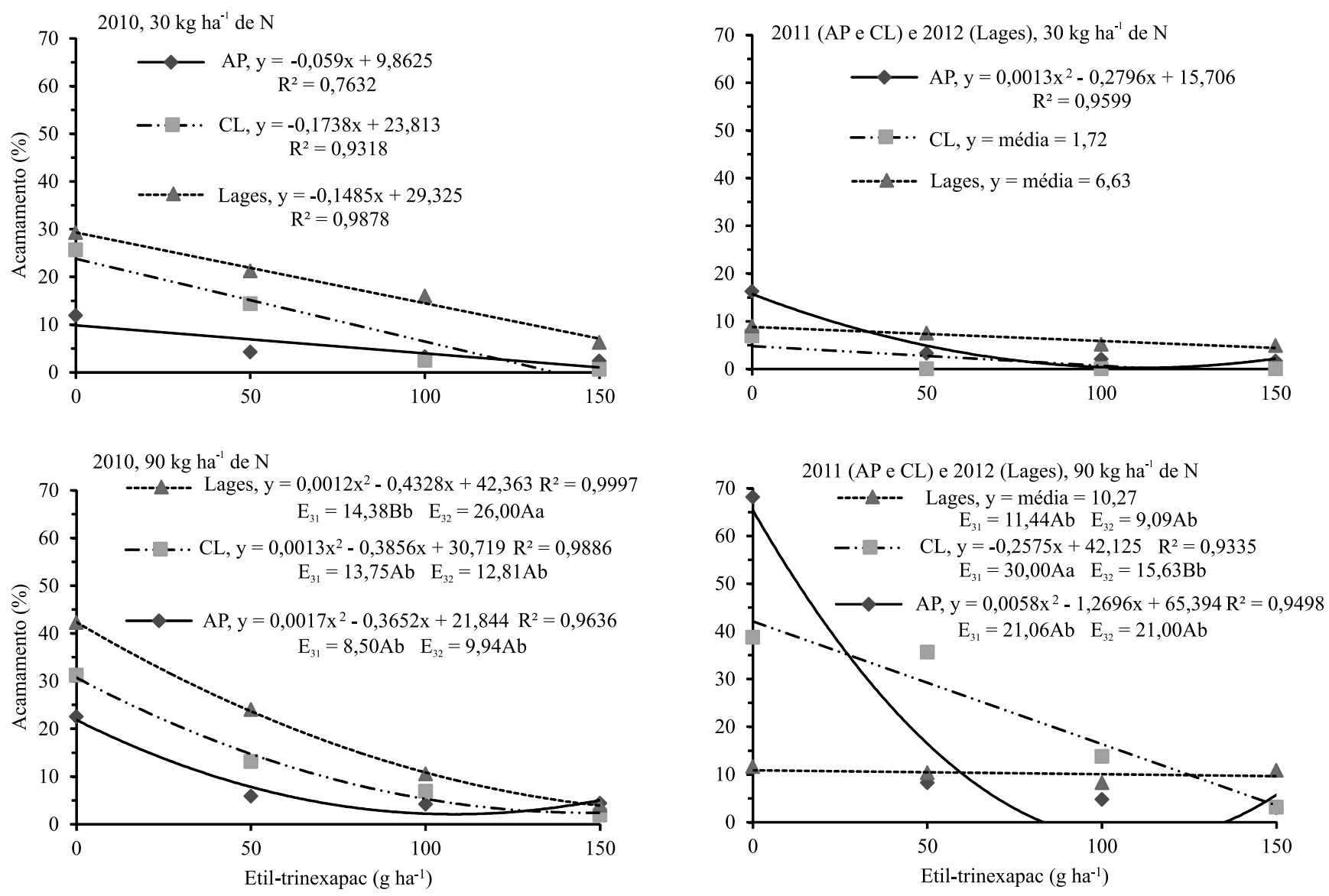

Figura 2. Percentagem de acamamento da aveia-branca (Avena sativa) 'Barbarasul' cultivada em diferentes ambientes, em resposta à aplicação de doses de etil-trinexapac nos estádios de primeiro e segundo nó visível, ou seja, nos estádios 31 (E E $_{31}$ ) e $32\left(\mathrm{E}_{32}\right)$ da escala de Zadoks (Zadoks et al., 1974). No cultivo com $90 \mathrm{~kg} \mathrm{ha}^{-1}$ de N, médias seguidas por letras diferentes, maiúsculas e minúsculas, diferem pelo teste de Tukey, a 5\% de probabilidade. Letras maiúsculas indicam a comparação entre épocas de aplicação num mesmo ambiente, e minúsculas, a comparação entre ambientes numa mesma época de aplicação. AP, Augusto Pestana, RS; CL, Capão do Leão, RS. 
na safra 2010, maiores índices de acamamento foram observados com a aplicação do etil-trinexapac no estádio $32\left(\mathrm{E}_{31}=14,4 \%\right.$ e $\left.\mathrm{E}_{32}=26 \%\right)$.

Houve efeito do ambiente de cultivo na produtividade de grãos, confirmado tanto pelo desempenho diferenciado da aveia-branca 'Barbarasul', em diferentes locais e níveis de adubação nitrogenada (Figura 3), quanto pelo elevado valor de quadrado médio observado para o fator ambiente na análise de variância (Tabela 3 ). Nas safras, para as mesmas condições de ambiente (local e adubação nitrogenada), observou-se relativa estabilidade de desempenho da produtividade de grãos, em que a aplicação do etil-trinexapac não proporcionou efeitos significativos. As condições edafoclimáticas do Município de Capão do Leão são caracteristicamente mais restritivas ao desenvolvimento da cultura da aveia-branca (solo mais arenoso e mais pobre em
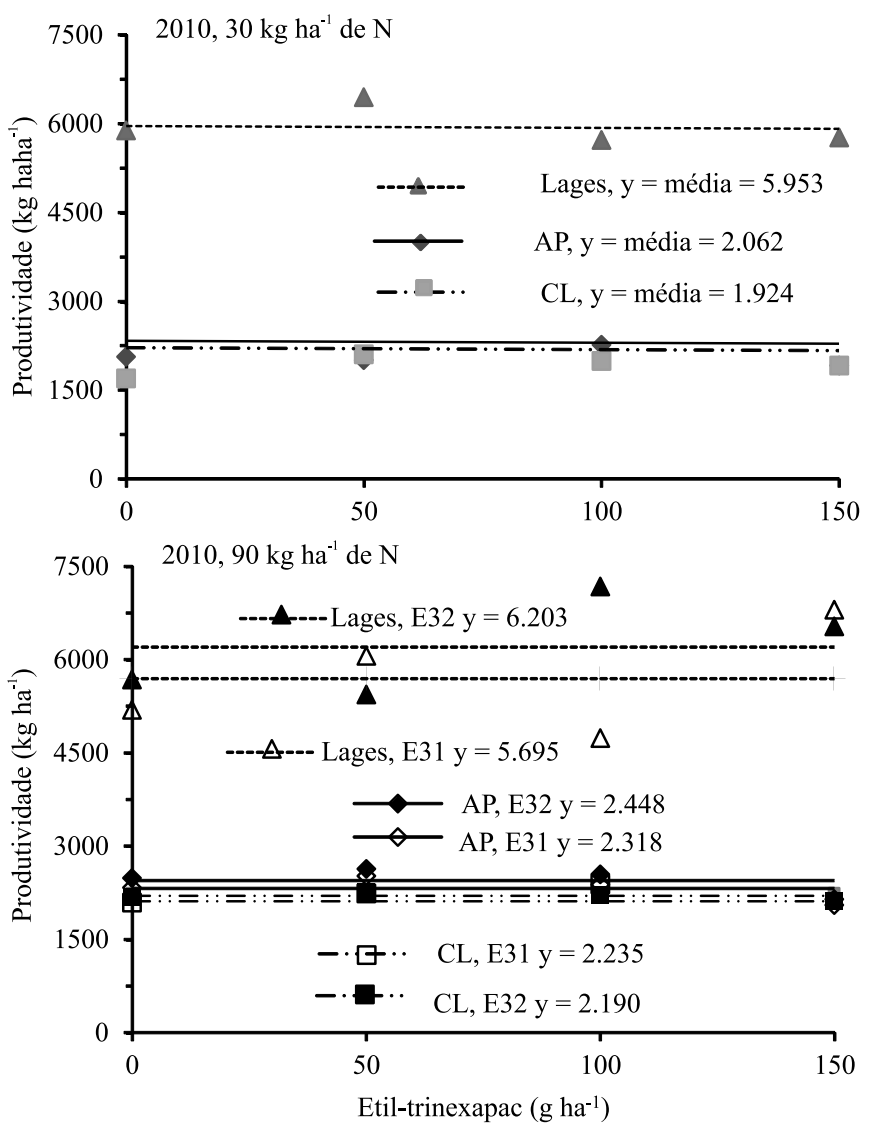

nutrientes) e muito favoráveis ao desenvolvimento de doenças de parte aérea (elevada umidade durante o ciclo de desenvolvimento da cultura). Assim, apesar do adequado manejo das plantas, justifica-se uma série histórica de desempenhos inferiores em produtividade de grãos em relação a outros locais de cultivo no Brasil (Crestani et al., 2010). Em Augusto Pestana, na safra 2010, as condições climáticas foram mais restritivas à aveia-branca (precipitação acumulada de 563,40 $\mathrm{mm}$ ) do que em 2011, ano considerado mais favorável ao desenvolvimento das culturas de inverno (precipitação acumulada de $813 \mathrm{~mm}$ ), tendo interferido, inclusive, no adequado aproveitamento do $\mathrm{N}$ disponibilizado via adubação, o que contribuiu para as diferenças em produtividade de grãos observadas entre safras com adubação com $90 \mathrm{~kg} \mathrm{ha}^{-1}$ de N.
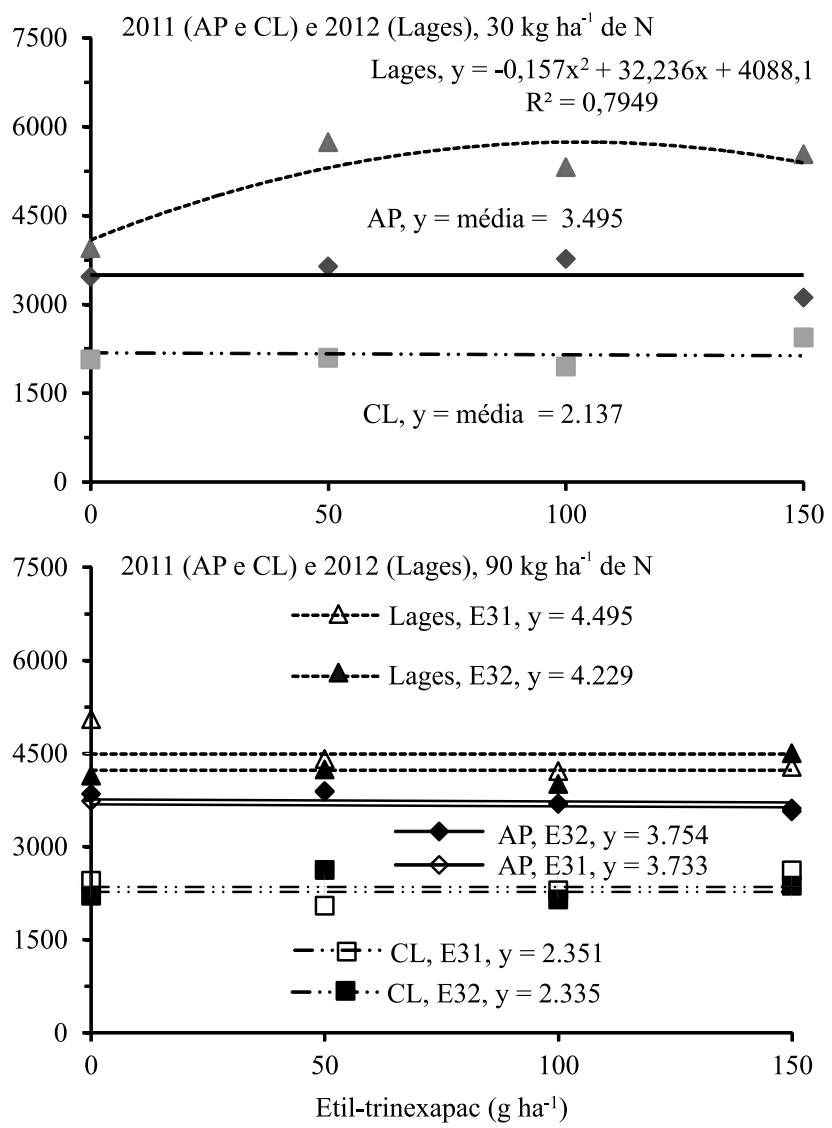

Figura 3. Produtividade de grãos da aveia-branca (Avena sativa) 'Barbarasul' cultivada em diferentes ambientes, em resposta à aplicação de doses de etil-trinexapac nos estádios de primeiro e segundo nó visível, ou seja, nos estádios $31\left(\mathrm{E}_{31}\right)$ e $32\left(\mathrm{E}_{32}\right)$ da escala de Zadoks (Zadoks et al., 1974). AP, Augusto Pestana, RS; CL, Capão do Leão, RS. 
Em Lages, na safra 2012 (30 kg ha-1 de N), onde a aplicação do regulador promoveu o aumento da produtividade de grãos, houve resposta quadrática em relação às concentrações testadas. Nessa condição, a maior produtividade foi evidenciada na dose de 102,7 $\mathrm{g} \mathrm{ha}^{-1}\left(6.142,8 \mathrm{~kg} \mathrm{ha}^{-1}\right)$. Vale destacar que as plantas foram colhidas manualmente e, portanto, mesmo em situações de intenso acamamento, as perdas em produtividade são minimizadas em relação à colheita mecanizada. Logo, a menor percentagem de plantas acamadas proporcionada pelo uso do etil-trinexapac em lavouras comerciais pode reduzir substancialmente as perdas de grãos com a colheita mecanizada.

A produtividade de grãos com a aplicação de etil-trinexapac e $90 \mathrm{~kg} \mathrm{ha}^{-1}$ de $\mathrm{N}$, com o segundo nó visível, em Lages, na safra 2010, foi superior à aplicação no momento de primeiro nó visível. Já na safra 2012, esse resultado foi obtido com uso do regulador quando as plantas apresentavam o primeiro nó visível (Figura 3). Nos demais ambientes testados, a época de aplicação não proporcionou diferenças significativas sobre a produtividade de grãos.

Os efeitos do etil-trinexapac sobre a produtividade de grãos variam de acordo com a cultura, o genótipo e a concentração utilizada (Berti et al., 2007; Zagonel \& Fernandes, 2007; Kappes et al., 2011; Penckowski et al., 2010; Arf et al., 2012; Souza et al., 2013). Ao avaliar quatro cultivares de arroz, Arf et al. (2012) verificaram ausência de resposta da cultivar BRS Soberana à aplicação do etil-trinexapac, mas que a IAC 202 apresentou efeitos lineares negativos, enquanto as cultivares BRS Primavera e Caiapó evidenciaram desempenho quadrático nas doses testadas $\left(0,50,100,150\right.$ e $\left.200 \mathrm{~g} \mathrm{ha}^{-1}\right)$. Zagonel \& Fernandes (2007) relataram tendência quadrática da produtividade de grãos em oito cultivares de trigo tratadas com diferentes doses de etil-trinexapac (0, $31,2,62,4,93,7,125,0$ e 156,2 $\mathrm{g} \mathrm{ha}^{-1}$ ). Dessa forma, a partir dos resultados obtidos no presente trabalho, pode-se deduzir que o uso do fitorregulador diminui o acamamento na aveia-branca, sem prejuízos à produtividade de grãos.

\section{Conclusões}

1. A aplicação do regulador de crescimento etil-trinexapac, nas doses de 100 a 150 g i.a. ha ${ }^{-1}$, reduz a altura das plantas e a percentagem de acamamento da aveia-branca (Avena sativa) 'Barbarasul'.
2. A aplicação do regulador de crescimento etil-trinexapac não exerce efeitos negativos na produtividade de grãos da cultivar de aveia-branca Barbarasul.

3. A intensidade da redução do acamamento depende das características do ambiente de cultivo.

\section{Agradecimentos}

À Coordenação de Aperfeiçoamento de Pessoal de Nível Superior (Capes), ao Conselho Nacional de Desenvolvimento Científico e Tecnológico (CNPq) e à Fundação de Amparo à Pesquisa do Estado do Rio Grande do Sul (Fapergs), pelo apoio financeiro e concessão de bolsas.

\section{Referências}

ARF, O.; NASCIMENTO, V. do; RODRIGUES, R.A.F.; ALVAREZ, R. de C.F.; GITTI, D. de C.; SÁ, M.E. de. Uso de etil-trinexapac em cultivares de arroz de terras altas. Pesquisa Agropecuária Tropical, v.42, p.150-158, 2012. DOI: 10.1590/ S1983-40632012000200008

BERRY, P.M.; GRIFFIN, J.M.; SYLVESTER-BRADLEY, R.; SCOTT, R.K.; SPINK, J.H.; BAKER, C.J.; CLARE, R.W. Controlling plant form through husbandry to minimise lodging in wheat. Field Crops Research, v.67, p.59-81, 2000. DOI: 10.1016/ S0378-4290(00)00084-8.

BERRY, P.M.; SPINK, J.H.; GAY, A.P.; CRAIGON, J. A comparison of root and stem lodging risks among winter wheat cultivars. The Journal of Agricultural Science, v.141, p.191-202, 2003. DOI: $10.1017 / \mathrm{S} 002185960300354 \mathrm{X}$

BERTI, M.; ZAGONEL, J.; FERNANDES, E.C. Produtividade de cultivares de trigo em função do trinexapac-ethyl e doses de nitrogênio. Scientia Agraria, v.6, p.127-134, 2007. DOI: 10.5380/ rsa.v8i2.8376.

CARVALHO, F.I.F. de; OLIVEIRA, A.C. de; VALÉRIO, I.P.; BENIN, G.; SCHMIDT, D.A.M.; HARTWIG, I.; RIBEIRO, G.; SILVEIRA, G. da. Barbarasul: a high-yielding and lodging-resistant white oat cultivar. Crop Breeding and Applied Biotechnology, v.9, p.96-99, 2009. DOI: 10.12702/1984-7033.v09n01a13.

COMISSÃO BRASILEIRA DE PESQUISA DE AVEIA. Indicações técnicas para cultura da aveia. Guarapuava: Fundação Agrária de Pesquisa Agropecuária, 2006. 82p.

CECCON, G.; GRASSI FILHO, H.; BICUDO, S.J. Rendimento de grãos de aveia branca (Avena sativa L.) em densidades de plantas e doses de nitrogênio. Ciência Rural, v.34, p.1723-1729, 2004. DOI: $10.1590 / \mathrm{S} 0103-84782004000600009$.

CRESTANI, M.; CARVALHO, F.I.F. de; OLIVEIRA, A.C. de; SILVA, J.A.G. da; GUTKOSKI, L.C.; SARTORI, J.F.; BARBIERI, R.L.; BARETTA, D. Conteúdo de $\beta$-glucana em cultivares de aveia-branca cultivadas em diferentes ambientes. Pesquisa Agropecuária Brasileira, v.45, p.261-268, 2010. DOI: 10.1590/ S0100-204X2010000300005. 
ESPINDULA, M.C.; ROCHA, V.S.; SOUZA, L.T. de; SOUZA, M.A. de; GROSSI, J.A.S. Efeitos de reguladores de crescimento na elongação do colmo de trigo. Acta Scientiarum. Agronomy, v.32, p.109-116, 2010. DOI: 10.4025/actasciagron.v32i1.943.

INSTITUTO BRASILEIRO DE GEOGRAFIA E ESTATÍSTICA. Levantamento sistemático da produção agrícola. 2014. Disponível em: $\quad<$ http://www.ibge.gov.br/home/estatistica/indicadores/ agropecuaria/lspa/defaulttab.shtm $>$. Acesso em: 5 fev. 2014.

KAPPES, C.; ARF, O.; ARF, M.V.; GITTI, D. de C.; ALCALDE, A.M. Uso de reguladores de crescimento no desenvolvimento e produção de crotalária. Pesquisa Agropecuária Tropical, v.41, p.508-518, 2011. DOI: 10.5216/pat.v41i4.10768.

KONG, E.; LIU, D.; GUO, X.; YANG, W.; SUN, J.; LI, X.; ZHAN, K.; CUI, D.; LIN, J.; ZHANG, A. Anatomical and chemical characteristics associated with lodging resistance in wheat. The Crop Journal, v.1, p.43-49, 2013. DOI: 10.1016/j.cj.2013.07.012. LÂNGARO, N.C.; AUGUSTIN, L.; FEDERIZZI, L.C.; PACHECO, M.T.; CARVALHO, F.I.F.; OLIVEIRA, A.C. de; SILVA, A.C.; ALMEIDA, J.L.; OLIVEIRA, J.C.; MOLIN, R.; GARRAFA, M.; CASTRO, R.L.; SOUZA, C.A.; SILVA, J.A.G.; RAMOS JUNIOR, E.U.; GODOY, R. Análise conjunta do ensaio brasileiro de cultivares de aveia branca, 2009. In: REUNIÃO DA COMISSÃO BRASILEIRA DE PESQUISA DE AVEIA, 30., 2010, São Carlos. Anais. São Carlos: Embrapa Pecuária Sudeste, 2010. p.381-400.

LÂNGARO, N.C.; FEDERIZZI, L.C.; PACHECO, M.T.; OLIVEIRA, A.C. de; SILVA, A.C. da; RIEDE, C.R.; ALMEIDA, J.L. de; OLIVEIRA, J.C.; MOLIN, R.; GARRAFA, M.; SOUZA, C.A. de; SILVA, J.A.G. da; BARROS, V.L.P. de; RAMOS JUNIOR, E.U.; OLIVEIRA, P.H. de. Análise conjunta do ensaio brasileiro de cultivares de aveia branca, 2012. In: REUNIÃO DA COMISSÃO BRASILEIRA DE PESQUISA DE AVEIA, 33., 2013, Pelotas. Anais. Pelotas: FAEM, 2013. Disponível em: $<$ http://cgfufpel.org/ aveia/trabalhos/238_1.pdf $>$. Acesso em: 16 dez. 2014.

MOES, J.; STOBBE, E.H. Barley treated with ethephon: I. Yield components and net grain yield. Agronomy Journal, v.83, p.86-90, 1991. DOI: 10.2134/agronj1991.00021962008300010021x.

MOHR, R.M.; GRANT, C.A.; MAY, W.E.; STEVENSON, F.C. The influence of nitrogen, phosphorus and potash fertilizer application on oat yield and quality. Canadian Journal of Soil Science, v.87, p.459-468, 2007. DOI: 10.4141/CJSS06022.

OLIVEIRA, A.C. de; CARVALHO, F.I.F. de; MAIA, L.C. da; SILVA, J.A.G. da; CRESTANI, M.; NORNBERG, R.; HARTWIG, I.; BENIN, G. FAEM Carlasul: new white oat cultivar with high grain yield. Crop Breeding and Applied Biotechnology, v.12, p.156-159, 2012a. DOI: 10.1590/S1984-70332012000200010.

OLIVEIRA, A.C. de; CARVALHO, F.I.F. de; MAIA, L.C. da; SILVA, J.A.G.; HAWERROTH, M.C.; NORNBERG, R.; SCHMIDT, D.A.M.; HARTWIG, I.; BENIN, G. FAEM Chiarasul: new white oat cultivar with high yield and grain processing quality. Crop Breeding and Applied Biotechnology, v.12, p.289-292, 2012b. DOI: 10.1590/S1984-70332012000200010.
OLIVEIRA, A.C. de; CRESTANI, M.; CARVALHO, F.I.F. de; SILVA, J.A.G.; VALÉRIO, I.P.; HARTWIG, I.; BENIN, G.; SCHMIDT, D.A.M.; BERTAN, I. Brisasul: a new high-yielding white oat cultivar with reduced lodging. Crop Breeding and Applied Biotechnology, v.11, p.370-374, 2011.

PENCKOWSKI, L.H.; ZAGONEL, J.; FERNANDES, E.C. Qualidade industrial do trigo em função do trinexapac-ethyl e doses de nitrogênio. Ciência e Agrotecnologia, v.34, p.1492-1499, 2010. DOI: 10.1590/S1413-70542010000600020.

RAJALA, A. Plant growth regulators to manipulate oat stands. Agriculture and Food Science, v.13, p.186-197, 2004. DOI: 10.2137/1239099041838058.

RAJALA, A.; PELTONEN-SAINIO, P. Plant growth regulator effects on spring cereal root and shoot growth. Agronomy Journal, v.93, p.936-943, 2001. DOI: 10.2134/agronj2001.934936x.

SANTOS, H.G. dos; JACOMINE, P.K.T.; ANJOS, L.H.C. dos; OLIVEIRA, V.A. de; OLIVEIRA, J.B. de; COELHO, M.R.; LUMBRERAS, J.F.; CUNHA, T.J.F. (Ed.). Sistema brasileiro de classificação de solos. 2.ed. Rio de Janeiro: Embrapa Solos, 2006. $306 \mathrm{p}$.

SAS INSTITUTE. Getting started with SAS learning edition. Cary: SAS Publishing, 2002. 86p.

SOUZA, C.A.; FIGUEIREDO, B.P.; COELHO, C.M.M.; CASA, R.C.; SANGOI, L. Arquitetura de plantas e produtividade da soja decorrente do uso de redutores de crescimento. Bioscience Journal, v.29, p.634-643, 2013.

TANHUANPÄÄ, P.; MANNINEN, O.; BEATTIE, A.; ECKSTEIN, P.; SCOLES, G.; ROSSNAGEL, B.; KIVIHARJU, E. An updated doubled haploid oat linkage map and QTL mapping of agronomic and grain quality traits from Canadian field trials. Genome, v.55, p.289-301, 2012. DOI: 10.1139/g2012-017.

TRIPATHI, S.C.; SAYRE, K.D.; KAUL, J.N.; NARANG, R.S. Growth and morphology of spring wheat (Triticum aestivum L.) culms and their association with lodging: effects of genotypes, $\mathrm{N}$ levels and ethephon. Field Crops Research, v.84, p.271-290, 2003. DOI: 10.1016/S0378-4290(03)00095-9.

WITKOWICZ, R. How do mineral fertilization and plant growth regulators affect yield and morphology of naked oat? Communications in Biometry and Crop Science, v.5, p.96-107, 2010 .

ZADOKS, J.C.; CHANG, T.T.; KONZAC, C.F. A decimal code for the growth stages of cereals. Weed Research, v.14, p.415-421, 1974. DOI: 10.1111/j.1365-3180.1974.tb01084.x.

ZAGONEL, J.; FERNANDES, E.C. Doses e épocas de aplicação de redutor de crescimento afetando cultivares de trigo em duas doses de nitrogênio. Planta Daninha, v.25, p.331-339, 2007. DOI: 10.1590/S0100-83582007000200013.

ZHU, L.; SHI, G.X.; LI, Z.S.; KUANG, T.; LI, B.; WEI, Q.; BAI, K.; HU, Y.; LIN, J. Anatomical and chemical features of high-yield wheat cultivar with reference to its parents. Acta Botanica Sinica, v.46, p.565-572, 2004.

Recebido em 8 de abril de 2014 e aprovado em 20 de janeiro de 2015 